\title{
Review Article \\ The Apolipoprotein E Antagonistic Pleiotropy Hypothesis: Review and Recommendations
}

\author{
Elizabeth R. Tuminello ${ }^{1}$ and S. Duke Han ${ }^{2}$ \\ ${ }^{1}$ Department of Psychology, Loyola University Chicago, Chicago, IL 60660, USA \\ ${ }^{2}$ Department of Behavioral Sciences, Rush University Medical Center, 1645 W. Jackson Boulevard, Suite 400, Chicago, \\ IL 60612, USA \\ Correspondence should be addressed to S. Duke Han, duke_han@rush.edu
}

Received 26 November 2010; Revised 3 January 2011; Accepted 4 January 2011

Academic Editor: Mikko Hiltunen

Copyright ( 2011 E. R. Tuminello and S. D. Han. This is an open access article distributed under the Creative Commons Attribution License, which permits unrestricted use, distribution, and reproduction in any medium, provided the original work is properly cited.

\begin{abstract}
Research on apolipoprotein E (APOE) has consistently revealed a relationship between the gene's $\varepsilon 4$ allele and risk for development of Alzheimer's disease (AD). However, research with younger populations of $\varepsilon 4$ carriers has suggested that the APOE $\varepsilon 4$ allele may in fact be beneficial in earlier ages and may only confer risk of cognitive decline later in life. Accordingly, we and others have proposed that APOE may represent an example of antagonistic pleiotropy. Antagonistic pleiotropy is an evolutionary biology concept that proposes certain genes or alleles that may differentially impact fitness during different life stages. We critically review this hypothesis in light of new research of the impact of APOE on cognition and neural integrity across the lifespan. We provide recommendations for the revision of the antagonistic pleiotropy hypothesis of APOE and suggest important avenues for future research in this area.
\end{abstract}

\section{Introduction}

Apolipoprotein E (APOE) is a protein coded by a gene located on chromosome 19 and plays an important role in cholesterol metabolism and synaptogenesis in the brain $[1,2]$. The APOE gene has three variants, or alleles: $\varepsilon 2$, $\varepsilon 3$, and $\varepsilon 4$. The $\varepsilon 4$ allele has been consistently associated with a higher risk of developing late-onset or sporadic Alzheimer's disease (AD) and a faster rate of disease progression (e.g., [3]), and as such is perhaps the most frequently studied genetic risk factor for AD. Studies of nondemented older adults utilizing event-related fMRI paradigms have also suggested that $\varepsilon 4$ carriers may more strongly recruit task-related brain regions or may recruit additional brain regions beyond task-related areas in order to compensate for preclinical $\mathrm{AD}$ changes to achieve the same performance as noncarriers (e.g., [4]). Preferentially recruited areas beyond task-related regions have frequently been found to include frontal regions with a possible predilection for the right hemisphere [1]. While $\varepsilon 4$ carriers may initially maintain cognitive performance through these compensatory recruitment processes, once $\mathrm{AD}$ disease burden increases, compensatory recruitment processes cannot sustain premorbid cognitive performance levels and cognitive decline ensues [1].

Although APOE has been extensively studied in older populations, its impact on cognition in younger ages has been seldom considered. Interestingly, the few studies that have investigated APOE's impact in early life have frequently reported that $\varepsilon 4$ carriers may cognitively outperform noncarriers. For instance, Yu et al. [5] found young $\varepsilon 4$ carriers to have higher IQs than noncarriers, Alexander et al. [6] found $\varepsilon 4$ carriers as young as six to have higher verbal fluency scores than noncarriers, and Wright et al. [7] found $\varepsilon 4$ infants to produce higher scores on the 24-month Mental Development Index of the Bayley Scale.

As we proposed previously in our review on this topic [1], these seemingly contradictory patterns of results may be reconciled through the antagonistic pleiotropy concept. Antagonistic pleiotropy is a concept from evolutionary biology purporting that certain genes may impact fitness (i.e., survival and reproduction) differently during different life stages. Utilizing the concept of antagonistic pleiotropy, 
we [1] suggested a model of the impact of APOE on cognition across the lifespan. According to this model, we have the following.

(a) Young $\varepsilon 4$ carriers outperform noncarriers on tests of memory and other cognitive domains.

(b) They may also recruit additional right hemisphere frontal regions in order to achieve this advantage.

(c) By middle age, there are slight if any neurocognitive differences between $\varepsilon 4$ carriers and noncarriers.

(d) In more advanced ages, $\varepsilon 4$ carriers may begin to preferentially recruit right frontal brain regions in order to maintain cognitive performance comparable to noncarriers.

Finally, the model proposes that once AD disease burden sufficiently accrues, $\varepsilon 4$ carriers' compensatory recruitment will begin to fail, marking the beginning of cognitive decline.

Much research investigating APOE across the lifespan has been conducted since the antagonistic pleiotropy hypothesis of APOE was proposed. We aim to review our model in light of this most recent research. We provide recommendations for revisions of this model to include recent findings and suggest important areas for future research to evaluate and expand the antagonistic pleiotropy hypothesis of APOE.

We utilized the PubMed database in searching the literature for this review. All searches were limited to those articles published in the last three years because of our intent to focus on research published following our proposal [1] of the antagonistic pleiotropy hypothesis of APOE in 2008. Search terms included "APOE and brain imaging," "APOE and cognition," and "APOE and neuropsychology." The abstracts of articles returned through these searches were examined and relevant articles were gathered. Articles were considered relevant if they examined APOE genotype in relation to cognitive performance or functional imaging in any age group. The reference lists of obtained articles were also searched by hand for additional relevant literature. The articles discussed in this review as well as their sample size, focus, and relevant findings are listed in Table 1.

\section{APOE and Cognition in Early Life}

Fortunately, research on the impact of APOE in early life has become more prevalent in recent years. However, this work has yielded inconsistent conclusions regarding the impact of APOE on cognition early in the lifespan. Consistent with the model of antagonistic pleiotropy, some studies have reported an $\varepsilon 4$ advantage in early life. Bloss et al. [8] found that school-age children with the $\varepsilon 4$ APOE allele performed better than children with the $\varepsilon 2$ allele on the Rey Complex Figure Test (RCFT) copy trial. Children with the $\varepsilon 2$ allele were also more likely than carriers of other alleles to be left-handed, a possible sign of abnormal neural development. Because of $\varepsilon 4$ carriers' apparent benefits and $\varepsilon 2$ carriers' deficits in this young sample, a reversal of typical findings in older age groups, the authors suggested that these results are consistent with antagonistic pleiotropy. Also in support, Mondadori [46] reported young adult $\varepsilon 4$ carriers to outperform noncarriers on the delayed recall portion of an episodic memory task, although no other differences by genotype were found in working memory, visuospatial processing, or executive functioning. Marchant et al. [9] reported that 18 to 30 -year-old APOE $\varepsilon 4$ carriers showed an advantage over noncarriers on tests of frontal lobe functioning. Noé et al. [10] studied a sample with moderate to severe traumatic brain injury (TBI) and found that while $\varepsilon 4$ carriers were more severe at baseline, they also exhibited a steeper rate of improvement in working memory compared to noncarriers. This work is consistent with our model [1], suggesting an advantage in cognition and head injury outcome for young $\varepsilon 4$ carriers.

Nevertheless, studies reporting the opposite findings are equally as prevalent. Gozal et al. [47] found that the APOE $\varepsilon 4$ allele was associated with cognitive impairment in 5to 7 -year-old children with obstructive sleep apnea. Dennis et al. [11] and Filbey et al. [12] both failed to find cognitive differences between $\varepsilon 4$ carriers and noncarriers in their 20's and 30's and Liu et al. [48] failed to find differences by APOE genotype in those younger than age 50. Hiekkanen et al. [13] also reported that APOE genotype was unassociated with one-year outcome of mild TBI in adults aged 18 to 70. Luciano et al. [14], studying a sample of 70-year olds in the Lothian Birth Cohort, failed to find differences by APOE genotype in IQ measured at age 11. It is noteworthy that several studies finding reduced cognition in $\varepsilon 4$ carriers only did so when carriers also had other risk factors for AD. For instance, Ruiz et al. [15] reported finding no differences in cognition by APOE status in a sample of adolescents. However, the authors discovered that $\varepsilon 4$ carriers who also carried the MTHFR 677TT allele, a gene possibly detrimental to cognition, displayed significantly worse cognitive performance than adolescents with other allelic combinations. Bloss et al. [16] found that school-age children with the APOE $\varepsilon 4$ allele as well as a family history of AD performed more poorly on standardized achievement tests of reading and language and the RCFT copy. Importantly, there was no main effect of APOE genotype; children with the $\varepsilon 4$ allele were only found to exhibit depressed scores when they also had a family history of $\mathrm{AD}$, suggesting that these two risk factors interact to influence cognition. Acevedo et al. [17] found that 7 to 10 -year-old $\varepsilon 4$ carriers were more likely to have been placed in an intensive care unit after birth, achieved lower spatial memory retention, and, among girls only, $\varepsilon 4$ carriers achieved lower visual recall scores on the Family Pictures Test. The authors conceptualized the latter finding as representing an interaction between the potentially gendered risk of $\mathrm{AD}$, which is more prevalent in women, with the $\mathrm{APOE} \varepsilon 4$ risk factor. It is important to note that while the authors indicated that participants' birth complications were unlikely to have impacted cognition, the presence of birth complications was not controlled for in analyses. Because $\varepsilon 4$ carriers were more likely to experience birth complications, this fact could explain the association between $\varepsilon 4$ status and cognition in this sample. 
TABLE 1: Samples, methods, and relevant findings of reviewed articles.

\begin{tabular}{lll}
\hline Article & Sample & Methods used \\
\hline $\begin{array}{l}\text { Bloss et al. } \\
{[8]}\end{array}$ & 147 youth, age 11-16 & $\begin{array}{l}\text { Assessment of verbal cognition and } \\
\text { visuospatial processing }\end{array}$ \\
\hline $\begin{array}{l}\text { Marchant } \\
\text { et al. [9] }\end{array}$ & $\begin{array}{l}\text { 156 college students, } \\
\text { age 18-30 }\end{array}$ & $\begin{array}{l}\text { Assessment of spatial working memory, } \\
\text { estimated IQ, immediate verbal memory, } \\
\text { verbal fluency, sustained attention, and } \\
\text { decision-making ability }\end{array}$ \\
\hline & $\begin{array}{l}\text { 82 patients currently } \\
\text { with post-traumatic } \\
\text { amnesia (PTA; mean } \\
\text { age }=31.5) \text { and 107 } \\
\text { patients without PTA } \\
\text { (mean age }=29.5)\end{array}$ & $\begin{array}{l}\text { Assessment of PTA severity, verbal memory, } \\
\text { and working memory }\end{array}$ \\
\hline 10$]$ & $\begin{array}{l}\text { Functional MRI during the encoding } \\
\text { portion of an object memory task followed } \\
\text { by a recall session 24 hours later, and an } \\
\text { assessment of memory, processing speed, } \\
\text { attention, and executive functioning }\end{array}$ \\
$\begin{array}{l}\text { Dennis et al. } \\
{[11]}\end{array}$ & $\begin{array}{l}\text { 24 young adults } \\
\text { (mean age }=21.3)\end{array}$ \\
\hline
\end{tabular}
age $19-32$
Filbey et al. 36 healthy adults, age [12] 50-75 and 16 adults,
Functional MRI during a visual working memory task and an assessment of global cognition
Relevant findings

APOE $\varepsilon 4$ carriers performed better than $\varepsilon 2$ carriers on a test of visuospatial processing

APOE $\varepsilon 4$ carriers showed an advantage over noncarriers on tests of verbal fluency and decision-making

APOE $\varepsilon 4$ carriers were more severe at baseline but exhibited a steeper rate of improvement in working memory over time than noncarriers

APOE $\varepsilon 4$ carriers and noncarriers performed similarly on all cognitivetests, while $\varepsilon 4$ carriers showed more bilateral MTL activity and functional connectivity of MTL and posterior cingulate and perilimbic structures during memory encoding

APOE $\varepsilon 4$ carriers and noncarriers did not differ in cognitive performance, while $\varepsilon 4$ carriers showed more medial frontal and MTL activity compared to noncarriers during the working memory task. Older $\varepsilon 4$ carriers also showed decreased activation compared to noncarriers in several frontal, parietal, temporal, and cingulate cortices

While MRI findings and PTA severity predicted

Structural MRI, assessment of PTA, and Glasgow Coma Scale ratings over a one year follow-up period

TBI outcome after one year, APOE genotype was unassociated with TBI outcome

Assessment of IQ at age 11 and measures of global cognition, working memory, nonverbal reasoning, construction, verbal fluency, and processing speed at age 70

APOE genotype was unrelated to IQ at age 11, yet the $\varepsilon 4$ allele was associated with lower processing speed, nonverbal reasoning, and general cognition measured at age 70

APOE genotype was not associated with cognition, but $\varepsilon 4$ carriers who also had the MTHFR 677TT allele had lower quantitative and reasoning abilities and problem solving ability

Ruiz et al. 412 participants, age

[15] 13-18

Assessment of verbal cognition and visuospatial processing

APOE genotype was not associated with cognition, but $\varepsilon 4$ carriers who also had a family history of AD had lower verbal and visuospatial abilities

Assessment of general intelligence, memory, attention, executive functioning, and visuospatial processing

APOE $\varepsilon 4$ carriers were more likely to have been placed in intensive care after birth and had lower spatial memory abilities, especially among girls APOE $\varepsilon 4$ carriers showed more connectivity among default-mode network regions and more hippocampal activation during the memory task than noncarriers

APOE $\varepsilon 4$ carriers had poorer memory performance than noncarriers. $\varepsilon 4$ carriers also more strongly activated prefrontal, temporal, and parietal regions during encoding than did noncarriers but showed less activation in prefrontal cortex during retrieval APOE $\varepsilon 4$ carriers showed increasing hippocampal activation with age during the memory task, while noncarriers showed age-related reductions in hippocampal activity

APOE genotype was unrelated to naming ability, yet $\varepsilon 4$ carriers exhibited greater activity in the left fusiform, right perisylvian cortex, and bilateral medial prefrontal cortex than noncarriers 
TABle 1: Continued.

\begin{tabular}{|c|c|c|c|}
\hline Article & Sample & Methods used & Relevant findings \\
\hline $\begin{array}{l}\text { Seidenberg } \\
\text { et al. [21] }\end{array}$ & $\begin{array}{l}69 \text { healthy older } \\
\text { adults, age } 65-85\end{array}$ & $\begin{array}{l}\text { Functional MRI during a semantic memory } \\
\text { task }\end{array}$ & $\begin{array}{l}\text { Those with an } \varepsilon 4 \text { allele and family history of } \mathrm{AD} \\
\text { showed greater activations in bilateral cingulate, } \\
\text { temporoparietal, and prefrontal regions than those } \\
\text { without risk factors. } \varepsilon 4 \text { carriers also showed greater } \\
\text { recruitment of right middle frontal regions }\end{array}$ \\
\hline $\begin{array}{l}\text { Woodard } \\
\text { et al. [22] }\end{array}$ & $\begin{array}{l}57 \text { older adults, age } \\
65-85 \text { with or } \\
\text { without amnestic } \\
\text { MCI }\end{array}$ & $\begin{array}{l}\text { Functional MRI during a semantic memory } \\
\text { task }\end{array}$ & $\begin{array}{l}\text { Those with an } \varepsilon 4 \text { allele and family history of AD } \\
\text { displayed increased activation in temporoparietal, } \\
\text { hippocampal, and posterior cingulate regions than } \\
\text { those without risk factors. MCI patients showed } \\
\text { similar patterns along with enhanced frontal } \\
\text { recruitment }\end{array}$ \\
\hline $\begin{array}{l}\text { Bartrés-Faz } \\
\text { et al. [23] }\end{array}$ & $\begin{array}{l}32 \text { older adults with } \\
\text { mild memory } \\
\text { impairments (mean } \\
\text { age }=66.83 \text { ) }\end{array}$ & $\begin{array}{l}\text { Functional MRI during a face-name } \\
\text { learning task }\end{array}$ & $\begin{array}{l}\text { APOE } \varepsilon 4 \text { carriers showed increased connectivity of } \\
\text { the hippocampus with anterior cingulate, } \\
\text { postcentral gyrus, and caudate nucleus during } \\
\text { encoding compared to noncarriers }\end{array}$ \\
\hline $\begin{array}{l}\text { Borghesani } \\
\text { et al. [24] }\end{array}$ & $\begin{array}{l}14 \text { healthy older } \\
\text { adults }\end{array}$ & $\begin{array}{l}\text { Functional MRI during a visuospatial } \\
\text { memory task }\end{array}$ & $\begin{array}{l}\text { APOE } \varepsilon 4 \text { carriers showed less MTL activation } \\
\text { during encoding than noncarriers despite equal } \\
\text { performance }\end{array}$ \\
\hline $\mathrm{Xu}$ et al. [25] & $\begin{array}{l}74 \text { healthy adults, age } \\
50-65\end{array}$ & $\begin{array}{l}\text { Functional MRI during an episodic face } \\
\text { recognition task }\end{array}$ & $\begin{array}{l}\text { APOE } \varepsilon 4 \text { carriers showed reduced activation in } \\
\text { posterior and anterior cingulate and precuneus } \\
\text { than noncarriers during recall }\end{array}$ \\
\hline $\begin{array}{l}\text { Suthana } \\
\text { et al. [26] }\end{array}$ & $\begin{array}{l}32 \text { healthy older } \\
\text { adults (mean age }= \\
61.1)\end{array}$ & Functional MRI during a word memory task & $\begin{array}{l}\text { APOE } \varepsilon 4 \text { carriers displayed reduced hippocampal } \\
\text { activation during encoding than noncarriers }\end{array}$ \\
\hline $\begin{array}{l}\text { Welsh- } \\
\text { Bohmer et al. } \\
{[27]}\end{array}$ & $\begin{array}{l}507 \text { healthy older } \\
\text { adults, age } 66-103\end{array}$ & $\begin{array}{l}\text { Assessment of object naming, verbal fluency, } \\
\text { memory, construction, processing speed, } \\
\text { and global cognition }\end{array}$ & $\begin{array}{l}\text { APOE genotype was unrelated to all measures of } \\
\text { cognition }\end{array}$ \\
\hline $\begin{array}{l}\text { Adamson } \\
\text { et al. }[28]\end{array}$ & $\begin{array}{l}50 \text { healthy pilots, age } \\
50-76\end{array}$ & Structural MRI and assessment of memory & $\begin{array}{l}\text { APOE } \varepsilon 4 \text { carriers performed more poorly on visual } \\
\text { paired associate recall than noncarriers but showed } \\
\text { no structural brain differences }\end{array}$ \\
\hline $\begin{array}{l}\text { Debette et al. } \\
\text { [29] }\end{array}$ & $\begin{array}{l}717 \text { healthy adult } \\
\text { offspring from the } \\
\text { Framingham cohort } \\
\text { (mean age }=59 \text { ) }\end{array}$ & $\begin{array}{l}\text { Structural MRI, assessment of memory, } \\
\text { abstract reasoning, and mental flexibility, } \\
\text { and determination of parental dementia }\end{array}$ & $\begin{array}{l}\text { APOE } \varepsilon 4 \text { carriers were more likely to have a parent } \\
\text { with dementia. Among } \varepsilon 4 \text { carriers, parental } \\
\text { dementia was associated with lower memory } \\
\text { performance }\end{array}$ \\
\hline $\begin{array}{l}\text { Honea et al. } \\
{[30]}\end{array}$ & $\begin{array}{l}53 \text { healthy older } \\
\text { adults age, } 60 \text { and } \\
\text { older }\end{array}$ & $\begin{array}{l}\text { Structural MRI, diffusion tensor imaging, } \\
\text { and an assessment of memory, language, } \\
\text { executive functioning, and visuospatial } \\
\text { ability }\end{array}$ & $\begin{array}{l}\text { APOE } \varepsilon 4 \text { carriers performed more poorly on } \\
\text { measures of memory and working memory and } \\
\text { had smaller hippocampi and parahippocampal FA }\end{array}$ \\
\hline $\begin{array}{l}\text { Caselli et al. } \\
{[31]}\end{array}$ & $\begin{array}{l}815 \text { healthy adults } \\
\text { age, } 21-97\end{array}$ & $\begin{array}{l}\text { A longitudinal assessment of long-term } \\
\text { memory, global cognition, verbal fluency, } \\
\text { and visuospatial abilities }\end{array}$ & $\begin{array}{l}\text { APOE } \varepsilon 4 \text { carriers were found to experience } \\
\text { memory decline in their } 50 \text { 's, while noncarriers did } \\
\text { not show decline until their } 70 \text { 's. A dose-dependent } \\
\text { effect was found in which } \varepsilon 4 \text { homozygotes } \\
\text { displayed earlier memory decline than } \\
\text { heterozygotes. } \varepsilon 4 \text { carriers showed steeper decline } \\
\text { than noncarriers in memory, global cognition, and } \\
\text { visuospatial processing }\end{array}$ \\
\hline $\begin{array}{l}\text { De Blasi } \\
\text { et al. }[32]\end{array}$ & $\begin{array}{l}620 \text { healthy older } \\
\text { adults, age } 65-85\end{array}$ & Assessment of memory and global cognition & $\begin{array}{l}\text { While APOE } \varepsilon 4 \text { was associated with memory } \\
\text { encoding and recall, it was unrelated to global } \\
\text { cognition }\end{array}$ \\
\hline $\begin{array}{l}\text { Knopman } \\
\text { et al. [33] }\end{array}$ & $\begin{array}{l}1130 \text { adults (mean } \\
\text { age }=59)\end{array}$ & $\begin{array}{l}\text { Assessment of memory, verbal fluency, } \\
\text { processing speed, and vascular risk factors }\end{array}$ & $\begin{array}{l}\text { APOE } \varepsilon 4 \text { carriers exhibited increased decline in } \\
\text { processing speed and memory compared to } \\
\text { noncarriers }\end{array}$ \\
\hline $\begin{array}{l}\text { Mungas } \\
\text { et al. [34] }\end{array}$ & $\begin{array}{l}369 \text { older adults } \\
(\text { mean age }=74.3)\end{array}$ & $\begin{array}{l}\text { Assessment of object naming, verbal fluency, } \\
\text { memory, and working memory }\end{array}$ & $\begin{array}{l}\text { APOE } \varepsilon 4 \text { carriers exhibited lower episodic memory } \\
\text { scores at baseline and increased decline in memory } \\
\text { and executive functioning than noncarriers }\end{array}$ \\
\hline $\begin{array}{l}\text { Walhovd } \\
\text { et al. [35] }\end{array}$ & $\begin{array}{l}161 \text { older adults, age } \\
55-90\end{array}$ & $\begin{array}{l}\text { Structural MRI, FDG-PET, and an } \\
\text { assessment of memory }\end{array}$ & $\begin{array}{l}\text { APOE } \varepsilon 4 \text { allele was associated with poorer } \\
\text { recognition memory beyond imaging variables }\end{array}$ \\
\hline
\end{tabular}


TABle 1: Continued.

\begin{tabular}{|c|c|c|c|}
\hline Article & Sample & Methods used & Relevant findings \\
\hline $\begin{array}{l}\text { Hayden et al. } \\
{[36]}\end{array}$ & $\begin{array}{l}2957 \text { older adults } \\
(\text { mean age }=74)\end{array}$ & $\begin{array}{l}\text { Longitudinal assessment of global cognition } \\
\text { and family history of dementia }\end{array}$ & $\begin{array}{l}\text { APOE } \varepsilon 4 \text { carriers had lower baseline global } \\
\text { cognitionand steeper decline in cognition than } \\
\text { noncarriers }\end{array}$ \\
\hline $\begin{array}{l}\text { Whitehair } \\
\text { et al. [37] }\end{array}$ & $\begin{array}{l}516 \text { amnestic MCI } \\
\text { patients, age } 55-90\end{array}$ & $\begin{array}{l}\text { Longitudinal assessment of global cognition, } \\
\text { memory, processing speed, verbal fluency, } \\
\text { working memory, naming, and functioning }\end{array}$ & $\begin{array}{l}\text { APOE } \varepsilon 4 \text { carriers had lower baseline scores on } \\
\text { nearly every assessment and also showed steeper } \\
\text { declines in nearly every domain }\end{array}$ \\
\hline $\begin{array}{l}\text { Yaffe et al. } \\
{[38]}\end{array}$ & $\begin{array}{l}2509 \text { healthy older } \\
\text { adults, age 70-79 }\end{array}$ & $\begin{array}{l}\text { Longitudinal assessment of global cognition } \\
\text { and health variables }\end{array}$ & $\begin{array}{l}\text { APOE } \varepsilon 4 \text { allele was associated with likelihood of } \\
\text { cognitive decline }\end{array}$ \\
\hline $\begin{array}{l}\text { Thambisetty } \\
\text { et al. [39] }\end{array}$ & $\begin{array}{l}94 \text { healthy older } \\
\text { adults (mean age }= \\
69.2)\end{array}$ & $\begin{array}{l}\text { Longitudinal structural MRI, PET imaging, } \\
\text { and assessment of memory, verbal } \\
\text { intelligence, verbal fluency, attention, } \\
\text { working memory, and executive functioning }\end{array}$ & $\begin{array}{l}\text { APOE } \varepsilon 4 \text { carriers performed more poorly on } \\
\text { category fluency and also had greater decline in } \\
\text { regional cerebral blood flow, particularly in areas } \\
\text { commonly implicated in AD }\end{array}$ \\
\hline Raz et al. [40] & $\begin{array}{l}189 \text { healthy adults, } \\
\text { age } 18-82\end{array}$ & $\begin{array}{l}\text { Assessment of fluid intelligence, memory, } \\
\text { executive functioning, and processing speed }\end{array}$ & $\begin{array}{l}\text { APOE } \varepsilon 4 \text { carriers evidenced greater age-related } \\
\text { interference effects in a Stroop task than } \\
\text { noncarriers }\end{array}$ \\
\hline $\begin{array}{l}\text { Barabash } \\
\text { et al. [41] }\end{array}$ & $\begin{array}{l}89 \text { amnestic MCI } \\
\text { patients (mean age }= \\
79) \text { and } 90 \text { healthy } \\
\text { adults (mean age }= \\
76)\end{array}$ & $\begin{array}{l}\text { Longitudinal assessment of cognitive } \\
\text { diagnosis }\end{array}$ & $\begin{array}{l}\text { APOE } \varepsilon 4 \text { allele was associated with higher risk of } \\
\text { developing MCI, but not } A D\end{array}$ \\
\hline $\begin{array}{l}\text { Wang et al. } \\
{[42]}\end{array}$ & $\begin{array}{l}20 \text { healthy older } \\
\text { adults (mean age }= \\
75) \text { and } 58 \text { amnestic } \\
\text { MCI patients (mean } \\
\text { age }=76.6 \text { ) }\end{array}$ & $\begin{array}{l}\text { Longitudinal structural MRI and an } \\
\text { assessment of global cognition, memory, } \\
\text { attention, language, construction, and } \\
\text { abstract thinking }\end{array}$ & $\begin{array}{l}\text { APOE } \varepsilon 4 \text { allele was unassociated with rate of } \\
\text { decline in cognition or brain volumes }\end{array}$ \\
\hline $\begin{array}{l}\text { Heun et al. } \\
{[43]}\end{array}$ & $\begin{array}{l}200 \text { healthy older } \\
\text { adults (mean age }= \\
80.3)\end{array}$ & $\begin{array}{l}\text { Longitudinal assessment of cognitive } \\
\text { diagnosis, global cognition, memory, } \\
\text { construction, attention, and language }\end{array}$ & $\begin{array}{l}\text { APOE } \varepsilon 4 \text { allele was unassociated with likelihood of } \\
\text { conversion to MCI }\end{array}$ \\
\hline $\begin{array}{l}\text { Carrión- } \\
\text { Baralt et al. } \\
{[44]}\end{array}$ & 87 nonagenarians & $\begin{array}{l}\text { Assessment of global cognition, memory, } \\
\text { naming, verbal fluency, attention, and } \\
\text { processing speed }\end{array}$ & $\begin{array}{l}\text { APOE } \varepsilon 4 \text { carriers displayed higher global cognition, } \\
\text { attention, visuospatial processing, naming, praxis, } \\
\text { and memory encoding than noncarriers }\end{array}$ \\
\hline $\begin{array}{l}\text { Kozauer } \\
\text { et al. [45] }\end{array}$ & $\begin{array}{l}659 \text { adults (mean age } \\
=58.4)\end{array}$ & $\begin{array}{l}\text { Longitudinal assessment of global cognition } \\
\text { and memory }\end{array}$ & $\begin{array}{l}\text { APOE } \varepsilon 4 \text { carriers in the younger cohort, who were } \\
\text { in their } 50 \text { 's, showed increased decline in memory } \\
\text { and global cognition compared to noncarriers. } \\
\text { However, older } \varepsilon 4 \text { carriers in their } 70 \text { 's showed no } \\
\text { cognitive differences from noncarriers }\end{array}$ \\
\hline
\end{tabular}

While these studies do not unequivocally support our model of antagonistic pleiotropy and APOE [1], interpretation of the findings of studies in this area is complicated by the nature of the samples studied. When the potential benefit of holding an $\varepsilon 4$ allele could be confined to a very narrow window early on in the lifespan, the importance of studying the impact of APOE in specific age ranges and of examining the interaction of age and APOE status in lifespan samples becomes apparent. Moreover, it is likely that APOE status interacts with other genetic and environmental risk factors (e.g., birth complications, MTHFR 677TT allele, family history of $\mathrm{AD}$ ) to impact cognition [15-17], implying that participants' additional risk factors beyond APOE should also be considered. Taking such measures will greatly clarify the literature in this area and lead to more reliable findings regarding the impact of APOE on cognition in early life.

\section{APOE and Compensatory Recruitment in Early Life}

Although comparatively less research has examined neural activity than cognition early in the lifespan, fMRI research with children has produced results more consistently supporting our model of antagonistic pleiotropy and APOE. Dennis et al. [11] examined activity in medial temporal lobe (MTL) structures important for memory and functional connectivity between MTL regions and other brain regions using event-related fMRI. Young adult participants were asked to encode visually presented stimuli and were given a surprise recall session 24 hours later. Results revealed that $\varepsilon 4$ carriers had more bilateral activity in MTL structures during memory encoding and had more functional connectivity of MTL structures with posterior cingulate and perilimbic 
regions than noncarriers. However, $\varepsilon 4$ carriers also showed a tendency towards decreased connectivity between anterior and posterior cortices. Dennis et al. [11] suggested that findings of increased functional connectivity between MTL regions and other regions known to be affected by $\mathrm{AD}$ (e.g., posterior cingulate) may suggest that APOE begins to be expressed in $\mathrm{AD}$-associated brain regions long before cognitive decline and that these findings may also be consistent with antagonistic pleiotropy. Filbey et al. [12, 49] also found that young adult $\varepsilon 4$ carriers showed more medial frontal [12, 49], cingulate [49], and MTL [12] activity compared to noncarriers in a working memory task. In a slightly older sample of 20-to-35-year-olds, Filippini et al. [18] reported $\varepsilon 4$ carriers to have more default mode network (DMN) connectivity and more hippocampal activation during a memory encoding task than noncarriers. However, at least one study [46] reported that young adult $\varepsilon 4$ carriers exhibited less neural activity in bilateral MTL and left frontal regions during the encoding and retrieval portions of an episodic memory task than performancematched noncarriers. The authors attributed these findings to enhanced neural efficiency of memory networks in young adult $\varepsilon 4$ carriers [46].

The majority of these studies appear to support the proposed model of antagonistic pleiotropy in that $\varepsilon 4$ carriers tend to recruit task-related regions more intensely than do noncarriers. However, the above studies provide less support for the proposal that $\varepsilon 4$ carriers will preferentially recruit more right hemisphere frontal regions during task performance. While it is unclear whether the $\varepsilon 4$ carriers studied by Dennis et al. [11] also showed higher activations in frontal regions because the authors focused on activity in MTL structures, Filippini et al. [18] used voxel-based morphometry and did not reveal any involvement of frontal regions by APOE status. Additionally, while Filbey et al. [12] indicated that $\varepsilon 4$ carriers recruited medial frontal regions more than noncarriers, this may be due to the nature of the task, as working memory tasks are more frontally-mediated than assessments of episodic or semantic memory.

\section{APOE and Compensatory Recruitment in Old Age}

As Trachtenberg et al. [50] note in their thorough review, research examining the blood-oxygen-level-dependent (BOLD) response using fMRI has produced inconsistent findings regarding the impact of APOE that are not easily understood even when considering differences in task, family history of $\mathrm{AD}$, and age. While this observation was also borne out in our review of recent research with older adults, the majority of studies provided evidence of compensatory neural recruitment in older APOE $\varepsilon 4$ carriers.

Of studies that found evidence of compensatory recruitment in nondemented older adults with the $\varepsilon 4$ allele, many found an increase in activation of task-related regions, regions known to be affected by $\mathrm{AD}$ (e.g., posterior cingulate), and frontal regions. For instance, Bookheimer et al. [51] found that nondemented middle-aged and older adult $\varepsilon 4$ carriers more strongly activated AD-associated brain regions, such as hippocampal, parietal, and prefrontal regions, than $\varepsilon 3$ carriers during a paired-associate word learning task. Furthermore, the authors found that the magnitude and extent of neural activation at baseline was predictive of cognitive decline after two years, as would be expected according to the compensatory recruitment hypothesis [51]. Dickerson et al. [52] also reported findings suggestive of compensatory recruitment in a sample of cognitively intact older adults and patients with MCI or $\mathrm{AD}$. Results revealed that APOE $\varepsilon 4$ carriers, regardless of diagnosis, showed enhanced hippocampal activity during encoding in a face-name memory task [52]. Similarly, Bondi et al. [53] reported healthy older adult $\varepsilon 4$ carriers display more intense and widespread activations in parietal, frontal, and right MTL regions than noncarriers during encoding in a picture learning task. Notably, $\varepsilon 4$ carriers exhibited reduced activations in left hippocampal regions compared to $\varepsilon 3$ carriers, supportive of our model's [1] prediction of a predilection for compensatory responses in the right hemisphere [53]. A more recent study by Kukolja et al. [4] found that nondemented older $\varepsilon 4$ carriers more strongly activated right hippocampal and predominantly right prefrontal, temporal, and parietal regions during the encoding portion of a spatial context memory task than did noncarriers, as would be expected according to antagonistic pleiotropy. However, the authors also reported that $\varepsilon 4$ carriers showed less activity in the prefrontal cortex bilaterally during retrieval. Interestingly, the authors noted that hippocampal activity was inversely associated with items remembered for $\varepsilon 4$ carriers but positively associated with recall for noncarriers. The opposite relationship was found in bilateral inferior frontal gyrus, right middle frontal gyrus, and left parietal cortex, the activity of which was positively associated with recall among $\varepsilon 4$ carriers. In light of these findings, Kukolja et al. [4] suggested that compensation may occur during encoding among $\varepsilon 4$ carriers, coinciding with increased frontal activations during this portion of the task. However, they note that activity decreases during the retrieval portion of the task reveal the likelihood of approaching cognitive decline. Filbey et al. [12] also found nondemented older adult $\varepsilon 4$ carriers to more strongly recruit medial frontal and temporal regions during a working memory task, although $\varepsilon 4$ carriers showed less activity than noncarriers in several other frontal and temporal regions. Trivedi et al. [19] examined a large sample from age 18 to 84 using an episodic encoding task and found that $\varepsilon 4$ carriers exhibited increases in hippocampal activity with age, while noncarriers showed age-related decreases in hippocampal activity. Wierenga et al. [20], studying cognitively intact older $\varepsilon 4$ carriers with a confrontation naming task, found that $\varepsilon 4$ carriers displayed increased activations compared to noncarriers in the left fusiform gyrus, bilateral medial prefrontal cortex, and right perisylvian cortex despite equal performance across the groups. Seidenberg et al. [21] utilized a semantic memory task designed to require low levels of effort and produce high accuracy rates in a cognitively normal sample of older adults. They found that those with the $\varepsilon 4$ allele and a family history of $\mathrm{AD}$ preferentially recruited bilateral posterior cingulate/precuneus, bilateral 
temporoparietal junction, and bilateral prefrontal cortex than participants without any $\mathrm{AD}$ risk factors during recall of familiar versus unfamiliar names. Moreover, in comparing participants with both the $\varepsilon 4$ allele and family history of $\mathrm{AD}$ to those with just a family history, $\varepsilon 4$ carriers exhibited more activation in right middle frontal and right supramarginal gyri. Seidenberg et al.'s [21] results suggest that the APOE $\varepsilon 4$ allele was uniquely associated with preferential activation of right hemisphere frontal regions, as we have suggested [1]. Woodard et al. [22] also used a low-effort famous name discrimination task and found that participants with an $\varepsilon 4$ allele and family history of $\mathrm{AD}$ displayed increased activation compared to those without risk factors in lateral temporoparietal regions, left hippocampus, and posterior cingulate/precuneus. Participants with MCI also showed similar increases in activations, but they did not show enhanced recruitment of the hippocampus and instead showed increased activations in frontal regions, suggesting that compensatory recruitment processes may evolve with changes in cognition and neuropathology burden [22]. Finally, Bartrés-Faz et al. [23] studied hippocampal connectivity in older adults with mild memory impairments. They reported that $\varepsilon 4$ carriers exhibited increased connectivity of the hippocampus with the anterior cingulate, inferior parietal/postcentral gyrus, and the caudate nucleus during the encoding portion of a face-name memory task. The authors suggested that this may indicate increased corticalsubcortical connections in the episodic memory networks in $\varepsilon 4$ carriers.

Overall, these studies uniformly support the presence of compensatory neural recruitment processes in $\varepsilon 4$ carriers. Yet, while some studies support our proposal [1] that $\varepsilon 4$ carriers would have a predilection for recruiting right hemisphere regions $[4,20,21]$, this was not true for all studies reviewed $[12,19,22,23]$. This could be a factor of type of task, as Kukolja et al. [4], who found the most evidence for a right hemisphere dominant compensatory response, used a spatial context memory task, which may be expected to preferentially activate right hemisphere regions due to the involvement of visuospatial processing. In contrast, several studies that found a predominantly left hemisphere or bilateral compensatory response (e.g., [12, 20-22]) used tasks (e.g., confrontation naming, working memory, and famous name discrimination) that may be more expected to activate left rather than right hemisphere regions due to the emphasis on language.

There were also studies reviewed which did not support the existence of a compensatory recruitment process in older cognitively intact $\varepsilon 4$ carriers. Johnson et al. [54] found that APOE genotype alone did not impact neural activity during a self-appraisal task in middle-age adults, although APOE status did interact with a family history of AD to produce greater frontal and posterior cingulate activations in $\varepsilon 4$ carriers without a family history of AD. Johnson et al. [55] reported similar results in an earlier study of middle-age adults using an episodic memory task. While APOE $\varepsilon 4$ carriers with no family history of AD did show the predicted enhanced recruitment of MTL structures, $\varepsilon 4$ carriers with a family history of AD actually showed the lowest levels of MTL recruitment of all participant groups [55]. As noted by the authors, $[54,55]$, such results suggest that the impact of APOE on brain activity may be moderated by genetic factors underlying a familial history of AD. Lind et al. [56] found that healthy middle aged and older adult $\varepsilon 4$ carriers displayed reduced neural activity in left inferior parietal and anterior cingulate cortices than noncarriers during a semantic categorization task. Borghesani et al. [24], studying MTL activation in nondemented older adults with a visuospatial memory task, also found that $\varepsilon 4$ carriers exhibited lower MTL activation during encoding. Filbey et al. [12], while simultaneously finding regions more activated in $\varepsilon 4$ carriers (as discussed above), also found that $\varepsilon 4$ carriers exhibited less activity than noncarriers in lateral frontal, basal ganglia, cingulate, parietal, and temporal regions during a working memory task. Reporting similar findings, $\mathrm{Xu}$ et al. [25] found that middle aged $\varepsilon 4$ carriers showed reduced activation in left dorsal posterior cingulate, precuneus, and anterior cingulate than noncarriers during the recall portion of an episodic face recognition task. A study by Suthana et al. [26] reported reduced hippocampal activation in nondemented older $\varepsilon 4$ carriers compared to noncarriers during the encoding portion of a word memory task. The authors proposed that this decrease in hippocampal activation may in fact allow for compensatory processes in other regions, which would explain findings of decreased activation in MTL regions in $\varepsilon 4$ carriers and may also explain Kukolja et al.'s [4] finding of reduced memory retrieval with increasing hippocampal activation among those with the $\varepsilon 4$ allele.

While many of these studies support the compensatory recruitment aspect of our model [1] of antagonistic pleiotropy and APOE, some studies did not find evidence of compensatory recruitment processes in $\varepsilon 4$ carriers, instead finding lower levels of activation in $\varepsilon 4$ carriers than noncarriers. A notable trend is that those studies finding decreased levels of activity in $\varepsilon 4$ carriers frequently did so in regions commonly associated with $\mathrm{AD}$ (e.g., posterior cingulate, precuneus, and hippocampus), while studies finding increased activity in $\varepsilon 4$ carriers commonly did so in regions beyond those typically involved in early $\mathrm{AD}$ (e.g., prefrontal cortex). As several authors have pointed out (e.g., [12]), $\varepsilon 4$ carriers may exhibit decrements in activity in regions initially impacted in $\mathrm{AD}$ due to increased pathology burden in these areas while continuing to compensate for these decrements with increased activity in regions not initially affected by $\mathrm{AD}$ pathological processes. Another possible explanation for discrepancies among studies could be due to differences in vascular risk factors present in the samples. Age-related vascular changes have been found to attenuate neurovascular coupling upon which the BOLD response in fMRI is based (e.g., [57, 58]). Such alterations can complicate the interpretation of the BOLD response and lead to erroneous conclusions if vascular changes are not taken into account [57]. This is particularly relevant as the APOE $\varepsilon 4$ allele has been associated with vascular risk factors (e.g., $[59,60])$. Therefore, careful consideration of vascular changes and clinically silent or prodromal forms of dementia 
are required to clarify the existence of compensatory neural recruitment in older adult $\varepsilon 4$ carriers.

\section{APOE and Declining Cognition in Old Age}

Much recent research has considered the implications of APOE genotype for declining cognition in old age, and the majority of this research has supported our proposal [1] of exaggerated cognitive decline in $\varepsilon 4$ carriers compared to noncarriers. While not universally the case $[12,21,27]$, most studies reporting cross-sectional differences by APOE genotype found that $\varepsilon 4$ carriers performed more poorly in tasks of verbal and visual episodic memory [4, 28-35, 59]. Other reported discrepancies were in working memory [30], general cognition [2, 4, 30, 36-38], category fluency [39], the Stroop task [40], matrix reasoning [14], and symbol search [14]. Many studies also considered cognition longitudinally and found $\varepsilon 4$ carriers to display an increased risk of developing mild cognitive impairment (MCI) (e.g., [41]), AD (e.g., [3]), or vascular dementia [59], although other studies have failed to find a relationship between the $\varepsilon 4$ allele and risk of developing MCI [42, 43]. Furthermore, although less consistent in the literature, some reported finding steeper rates of cognitive decline in $\varepsilon 4$ carriers compared to noncarriers $[3,31,36,37]$, with a number reporting evidence of a dose-dependent response $[3,31,59]$. One interesting study by Casselli et al. [31] longitudinally followed patients between 21 and 97 years of age. Growth curve modeling predicted that APOE $\varepsilon 4$ carriers begin to decline in their memory around their 50's, while participants without an $\varepsilon 4$ allele only begin to experience memory decline in their 70's. Memory decline also evidenced a dosedependent relationship, so that participants with two $\varepsilon 4$ alleles were predicted to experience memory decline before those with only one $\varepsilon 4$ allele. Moreover, $\varepsilon 4$ carriers had an overall steeper rate of decline in memory, on the MMSE, and on Judgment of Line Orientation than noncarriers. Importantly, the study's longitudinal design allowed authors to remove from analysis those participants who eventually developed MCI or dementia. The authors therefore suggest that APOE detrimentally affects cognition in older adults independent of the influence of dementia. Liu et al. [48] also examined the impact of the APOE $\varepsilon 4$ allele on cognition in a lifespan sample and reported that $\varepsilon 4$ carriers' cognitive performance was only reduced compared to noncarriers in those 50 and older; APOE $\varepsilon 4$ had no effect on cognition in younger age groups.

Carrión-Baralt et al. [44] reported intriguing results with a sample of Puerto Rican oldest-old. They found $\varepsilon 4$ carriers in this sample of nonagenarians to exhibit higher performance than noncarriers in overall cognition as well as measures of visuospatial abilities, naming, and attention. The authors suggest that this unexpected finding may have two sources. It may be that those who survive into their 90's have genetic protective factors that confer benefit regardless of APOE genotype. Because of the higher risk of dementia and eventual mortality found with $\varepsilon 4$ carriers, nonagenarian $\varepsilon 4$ carriers who survived beyond the prime ages for $A D$ development may be more likely to have this protective factor and may therefore perform better than noncarriers. A second possibility noted by Carrión-Baralt et al. [44] is that APOE may exhibit antagonistic pleiotropic effects, being detrimental for cognition and survival in young-old age, but being beneficial in old-old age. Reporting similar findings, Kozauer et al. [45] studied a large sample of two age cohorts after a 22-year followup. Differences in cognition by APOE status were only found in the younger cohort, which was in their 50's, in which $\varepsilon 4$ carriers displayed worse performance than noncarriers. These differences were not found at other waves of data collection, implying that they developed upon reaching middle and older ages. Interestingly, cognitive differences by APOE status were not observed in the older cohort, which had a mean age in the mid-70's. This also supports the contention that the APOE $\varepsilon 4$ allele may not be detrimental to those who survive into later ages without developing dementia. Similarly, Welsh-Bohmer et al. [27], who also studied APOE in oldest-old, found no relationship between APOE and cognition. While these latter findings of cognitive similarity by APOE status in the oldest-old may not be as persuasive as those of Carrión-Baralt et al. [44], they still suggest that the very common finding of cognitive decline in older $\varepsilon 4$ carriers may not hold true for the oldestold and may fail to do so because of antagonistic pleiotropy. This argues for an extension of our model [1] into old-old age, where APOE $\varepsilon 4$ may again impart beneficial cognitive effects to its carriers.

As suggested in our [1] model of APOE as an example of antagonistic pleiotropy, much research has found that the APOE $\varepsilon 4$ allele is associated with disproportionate cognitive decline in old age $[3,4,14,28-41,59]$, although it may be that the $\varepsilon 4$ allele confers an advantage on its carriers who reach old-old age without developing dementia, suggesting an extension to our model [1, 27, 45, 48]. The association of APOE $\varepsilon 4$ with cognitive decline follows from findings suggesting a close relationship of the $\varepsilon 4$ allele with amyloid neuropathology, a hallmark of AD [61-65]. Indeed, many individual studies and reviews have reported APOE to be strongly associated with $A \beta 42$, the most insoluble form of the $\mathrm{A} \beta$ peptide, which aggregates to form senile plaques in $\mathrm{AD}$ (e.g., $[61,64,65])$. Some studies have also demonstrated a dose-dependent relationship between the APOE $\varepsilon 4$ allele and amyloid pathology, in which $\varepsilon 4$ homozygotes exhibit more amyloid pathology than those with only one $\varepsilon 4$ allele (e.g., $[64,65])$. However, the demonstrated relationship between the APOE $\varepsilon 4$ allele and AD-related amyloid pathology might argue against the ability of APOE to confer protective effects to its old-old nondemented carriers. With respect to this possibility, it is important to note that studies have found that amyloid pathology, while being strongly associated with the development of $\mathrm{AD}$, does not account for all of the cognitive decline found in these patients (e.g., [61, 65, 66]). Other biomarkers, particularly brain atrophy and tau pathology, commonly account for a large portion of variance in cognitive decline found in $\mathrm{AD}$ (e.g., $[61,65,66]$ ). The fact that the APOE $\varepsilon 4$ allele has not been as strongly associated with these other AD biomarkers $[61,65,66]$ may explain why old-old APOE $\varepsilon 4$ carriers may still exhibit cognitive benefits 
despite the strong association of the $\varepsilon 4$ allele with amyloid pathology.

\section{Conclusions and Recommendations}

Our model [1] of antagonistic pleiotropy in APOE was critically re-evaluated in light of recent research. Some aspects of the model were strongly supported. Research suggests that younger $\varepsilon 4$ carriers do indeed exhibit compensatory neural recruitment, as proposed by our model [1]. However, our prediction of a predilection for right hemisphere frontal regions in this compensatory process was not clearly corroborated. It instead seems that young $\varepsilon 4$ carriers invoke compensatory processes in task-related regions. The cognitive decline in older $\varepsilon 4$ carriers predicted by the model was also supported in recent literature, revealing a strong effect on memory as well as other cognitive domains. Yet inconsistent evidence was found to support other aspects of the model. For instance, the presence of compensatory neural recruitment in older $\varepsilon 4$ carriers was not unanimously supported. Studies with older $\varepsilon 4$ carriers also only partially supported our prediction [1] of a higher likelihood of recruitment of right frontal regions. Differences in compensatory regions may be linked to type of task, as those thought to invoke more of a right hemisphere response also found evidence for right hemisphere compensatory processes, while left hemisphere compensatory processes were occasionally observed for tasks emphasizing language that would be thought to rely more heavily on left hemisphere regions. It is also unclear whether young $\varepsilon 4$ carriers show better cognitive performance than noncarriers. As discussed, these inconsistent findings may be explained by the need to consider APOE and cognition in narrow age ranges or to statistically test the interaction between APOE genotype and age in predicting cognition for lifespan samples. It also appears important to control for detrimental health comorbidities that may be more prevalent in $\varepsilon 4$ carriers in such analyses. However, if it is determined that APOE $\varepsilon 4$ carriers do not show a cognitive benefit in early life, this strongly argues against APOE as displaying antagonistic pleiotropic effects. In fact, findings of compensatory recruitment in young $\varepsilon 4$ carriers in the presence of similar, instead of enhanced, cognitive performance implies that the $\varepsilon 4$ allele may be detrimental even in young ages, as young carriers have to activate more brain regions to produce the same level of performance as noncarriers. Research in this area is vital to further evaluate the antagonistic pleiotropy hypothesis of APOE.

In light of the reviewed research, we suggest certain revisions to our model [1] of antagonistic pleiotropy and APOE. In the absence of conclusive contrary findings, we maintain that APOE $\varepsilon 4$ carriers exhibit cognitive benefits early in life. We also propose that compensatory neural recruitment processes occur in task-related regions in young $\varepsilon 4$ carriers but transfer to frontal regions among older adults, once task-related regions become overburdened with $\mathrm{AD}$ pathology. While compensatory regions may be in the right hemisphere, lateralization of the compensatory response does not seem to be a consistent trend. Second, we propose that cognitive decline will begin much earlier in $\varepsilon 4$ carriers and will progress more rapidly. In light of new research $[27,44,45]$, we also predict that the APOE $\varepsilon 4$ allele again becomes beneficial in the oldest-old, who survive into oldold age without developing dementia. Additional research is needed to test this notion, as functional imaging to examine compensatory recruitment in nonagenarian populations of $\varepsilon 4$ carriers would be particularly elucidating.

The finding of cognitive superiority in nondemented $\varepsilon 4$ nonagenarians suggests a second hypothesis of gene-gene interaction that may explain the apparent APOE antagonistic pleiotropic effects as well as the inconsistencies in the literature. It may be that the APOE $\varepsilon 4$ allele is not antagonistically pleiotropic but instead interacts with other $\mathrm{AD}$ risk factors to differentially influence cognition depending on a person's profile of risk. Indeed, APOE has been found by many studies to interact with a family history of AD to influence cognition (e.g., $[25,29])$ and also to interact with other risk genes such as APOCI AA, BCHE, and CHRNA4 $[59,67,68]$. Therefore, it may be that among people without AD risk factors, APOE $\varepsilon 4$ does not adversely affect cognition and could perhaps be beneficial to its carriers. Some have gone so far as to suggest that APOE has no influence on cognition beyond increasing risk for $\mathrm{AD}$ [69]. These authors suggest that APOE, while putting one at risk for prodromal dementia, does not create a specific cognitive phenotype of its own [69]. APOE's interaction with other genetic risk factors to influence cognition would explain why only some young $\varepsilon 4$ carriers show enhanced cognition over noncarriers, why only some $\varepsilon 4$ carriers show disproportionate cognitive declines with age, and why nondemented oldest-old $\varepsilon 4$ carriers show cognitive enhancements. Perhaps those children with APOE $\varepsilon 4$ and other AD risk factors are those that show no difference from noncarriers, due to compensatory recruitment processes, or actually show reductions in cognitive abilities compared to noncarriers. Perhaps those children with APOE $\varepsilon 4$ and other AD risk factors are the ones to show disproportionate cognitive decline in old age compared to noncarriers, whereas $\varepsilon 4$ carriers without other risk factors do not show more cognitive decline than would be expected. This hypothesis of the interaction of APOE with AD-specific risk factors is further supported by the lack of associations between APOE and cognition in other diseases such as multiple sclerosis [70]. Future research in genetics and epigenetics is needed which carefully considers participants' $\mathrm{AD}$ risk profiles. Careful, comprehensive studies conducted in this way will help the field determine whether APOE displays antagonistic pleiotropy or gene-gene interactions with other AD risk factors.

This paper suggests several avenues for future research as well as other important factors when considering APOE as an example of antagonistic pleiotropy. Beyond considering neurovascular decoupling with age and participants' $\mathrm{AD}$ risk profiles, future research examining the impact of APOE $\varepsilon 4$ allele on cognition and neural activity across the lifespan is needed. Continued evaluation of the antagonistic pleiotropy and gene-gene interaction hypotheses of APOE will move the field closer to realizing effective treatments and preventative measures for $\mathrm{AD}$. 


\section{References}

[1] S. D. Han and M. W. Bondi, "Revision of the apolipoprotein E compensatory mechanism recruitment hypothesis," Alzheimer's and Dementia, vol. 4, no. 4, pp. 251-254, 2008.

[2] U. Beffert, M. Danik, P. Krzywkowski, C. Ramassamy, F. Berrada, and J. Poirier, "The neurobiology of apolipoproteins and their receptors in the CNS and Alzheimer's disease," Brain Research Reviews, vol. 27, no. 2, pp. 119-142, 1998.

[3] E. S. Blom, V. Giedraitis, H. Zetterberg et al., "Rapid progression from mild cognitive impairment to alzheimer's disease in subjects with elevated levels of tau in cerebrospinal fluid and the Apoe $\varepsilon 4 / \varepsilon 4$ genotype," Dementia and Geriatric Cognitive Disorders, vol. 27, no. 5, pp. 458-464, 2009.

[4] J. Kukolja, C. M. Thiel, T. Eggermann, K. Zerres, and G. R. Fink, "Medial temporal lobe dysfunction during encoding and retrieval of episodic memory in non-demented APOE $\varepsilon 4$ carriers," Neuroscience, vol. 168, no. 2, pp. 487-497, 2010.

[5] Y. W. Y. Yu, C. H. Lin, S. P. Chen, C. J. Hong, and S. J. Tsai, "Intelligence and event-related potentials for young female human volunteer apolipoprotein E $\varepsilon 4$ and non- $\varepsilon 4$ carriers," Neuroscience Letters, vol. 294, no. 3, pp. 179-181, 2000.

[6] D. M. Alexander, L. M. Williams, J. M. Gatt et al., "The contribution of apolipoprotein $\mathrm{E}$ alleles on cognitive performance and dynamic neural activity over six decades," Biological Psychology, vol. 75, no. 3, pp. 229-238, 2007.

[7] R. O. Wright, H. Hu, E. K. Silverman et al., "Apolipoprotein E genotype predicts 24-month bayley scales infant development score," Pediatric Research, vol. 54, no. 6, pp. 819-825, 2003.

[8] C. S. Bloss, D. C. Delis, D. P. Salmon, and M. W. Bondi, "APOE genotype is associated with left-handedness and visuospatial skills in children," Neurobiology of Aging, vol. 31, no. 5, pp. 787-795, 2010.

[9] N. L. Marchant, S. L. King, N. Tabet, and J. M. Rusted, "Positive effects of cholinergic stimulation favor young APOE $\eta 4$ carriers," Neuropsychopharmacology, vol. 35, no. 5, pp. 1090-1096, 2010.

[10] E. Noé, J. Ferri, C. Colomer, B. Moliner, and J. Chirivella, "APOE genotype and verbal memory recovery during and after emergence from post-traumatic amnesia," Brain Injury, vol. 24, no. 6, pp. 886-892, 2010.

[11] N. A. Dennis, J. N. Browndyke, J. Stokes et al., "Temporal lobe functional activity and connectivity in young adult APOE $\varepsilon 4$ carriers," Alzheimer's and Dementia, vol. 6, no. 4, pp. 303-311, 2010.

[12] F. M. Filbey, G. Chen, T. Sunderland, and R. M. Cohen, "Failing compensatory mechanisms during working memory in older apolipoprotein E- $\varepsilon 4$ healthy adults," Brain Imaging and Behavior, vol. 4, no. 2, pp. 177-188, 2010.

[13] H. Hiekkanen, T. Kurki, N. Brandstack, V. Kairisto, and O. Tenovuo, "Association of injury severity, MRI-results and ApoE genotype with 1-year outcome in mainly mild TBI: a preliminary study," Brain Injury, vol. 23, no. 5, pp. 396-402, 2009.

[14] M. Luciano, A. J. Gow, S. E. Harris et al., "Cognitive ability at age 11 and 70 years, information processing speed, and APOE variation: the Lothian Birth Cohort 1936 study," Psychology and Aging, vol. 24, no. 1, pp. 129-138, 2009.

[15] J. R. Ruiz, R. Castillo, I. Labayen et al., "Individual and combined effects of ApoE and MTHFR 677C/T polymorphisms on cognitive performance in Spanish adolescents: the AVENA study," Journal of Pediatrics, vol. 156, no. 6, pp. 978-984, 2010.

[16] C. S. Bloss, D. C. Delis, D. P. Salmon, and M. W. Bondi, "Decreased cognition in children with risk factors for
Alzheimer's disease," Biological Psychiatry, vol. 64, no. 10, pp. 904-906, 2008.

[17] S. F. Acevedo, B. J. Piper, M. J. Craytor, T. S. Benice, and J. Raber, "Apolipoprotein E4 and sex affect neurobehavioral performance in primary school children," Pediatric Research, vol. 67 , no. 3, pp. 293-299, 2010.

[18] N. Filippini, B. J. MacIntosh, M. G. Hough et al., "Distinct patterns of brain activity in young carriers of the APOE- $\varepsilon 4$ allele," Proceedings of the National Academy of Sciences of the United States of America, vol. 106, no. 17, pp. 7209-7214, 2009.

[19] M. A. Trivedi, T. W. Schmitz, M. L. Ries et al., "fMRI activation during episodic encoding and metacognitive appraisal across the lifespan: Risk factors for Alzheimer's disease," Neuropsychologia, vol. 46, no. 6, pp. 1667-1678, 2008.

[20] C. E. Wierenga, N. H. Stricker, A. McCauley et al., "Increased functional brain response during word retrieval in cognitively intact older adults at genetic risk for Alzheimer's disease," NeuroImage, vol. 51, no. 3, pp. 1222-1233, 2010.

[21] M. Seidenberg, L. Guidotti, K. A. Nielson et al., "Semantic memory activation in individuals at risk for developing Alzheimer disease," Neurology, vol. 73, no. 8, pp. 612-620, 2009.

[22] J. L. Woodard, M. Seidenberg, K. A. Nielson et al., "Semantic memory activation in amnestic mild cognitive impairment," Brain, vol. 132, no. 8, pp. 2068-2078, 2009.

[23] D. Bartrés-Faz, J. M. Serra-Grabulosa, F. T. Sun et al., "Functional connectivity of the hippocampus in elderly with mild memory dysfunction carrying the APOE $\varepsilon 4$ allele," Neurobiology of Aging, vol. 29, no. 11, pp. 1644-1653, 2008.

[24] P. R. Borghesani, L. C. Johnson, A. L. Shelton et al., "Altered medial temporal lobe responses during visuospatial encoding in healthy APOE*4 carriers," Neurobiology of Aging, vol. 29, no. 7, pp. 981-991, 2008.

[25] G. Xu, D. G. Mclaren, M. L. Ries et al., "The influence of parental history of Alzheimer's disease and apolipoprotein E $\varepsilon 4$ on the BOLD signal during recognition memory," Brain, vol. 132, no. 2, pp. 383-391, 2009.

[26] N. A. Suthana, A. Krupa, M. Donix et al., "Reduced hippocampal CA2, CA3, and dentate gyrus activity in asymptomatic people at genetic risk for Alzheimer's disease," NeuroImage, vol. 53, no. 3, pp. 1077-1084, 2010.

[27] K. A. Welsh-Bohmer, T. Ostbye, L. Sanders et al., "Neuropsychological performance in advanced age: influences of demographic factors and apolipoprotein E: findings from the Cache County memory study," Clinical Neuropsychologist, vol. 23, no. 1, pp. 77-99, 2009.

[28] M. M. Adamson, K. M. Landy, S. Duong et al., "Apolipoprotein E epsilon4 influences on episodic recall and brain structures in aging pilots," Neurobiology of Aging, vol. 31, no. 6, pp. 1059-1063, 2010.

[29] S. Debette, P. A. Wolf, A. Beiser et al., "Association of parental dementia with cognitive and brain MRI measures in middleaged adults," Neurology, vol. 73, no. 24, pp. 2071-2078, 2009.

[30] R. A. Honea, E. Vidoni, A. Harsha, and J. M. Burns, "Impact of APOE on the healthy aging brain: a voxel-based MRI and DTI study," Journal of Alzheimer's Disease, vol. 18, no. 3, pp. 553-564, 2009.

[31] R. J. Caselli, A. C. Dueck, D. Osborne et al., "Longitudinal growth modeling of cognitive aging and the APOE e4 effect," The New England Journal of Medicine, vol. 361, no. 3, pp. 255263, 2009.

[32] S. De Blasi, A. Montesanto, C. Martino et al., "APOE polymorphism affects episodic memory among non demented 
elderly subjects," Experimental Gerontology, vol. 44, no. 3, pp. 224-227, 2009.

[33] D. S. Knopman, T. H. Mosley, D. J. Catellier, and L. H. Coker, "Fourteen-year longitudinal study of vascular risk factors, APOE genotype, and cognition: the ARIC MRI Study," Alzheimer's and Dementia, vol. 5, no. 3, pp. 207-214, 2009.

[34] D. Mungas, L. Beckett, D. Harvey et al., "Heterogeneity of cognitive trajectories in diverse older persons," Psychology and Aging, vol. 25, no. 3, pp. 606-619, 2010.

[35] K. B. Walhovd, A. M. Fjell, A. M. Dale et al., "Multi-modal imaging predicts memory performance in normal aging and cognitive decline," Neurobiology of Aging, vol. 31, no. 7, pp. 1107-1121, 2010.

[36] K. M. Hayden, P. P. Zandi, N. A. West et al., "Effects of family history and apolipoprotein $\mathrm{E} \varepsilon 4$ status on cognitive decline in the absence of Alzheimer dementia: the cache county study," Archives of Neurology, vol. 66, no. 11, pp. 1378-1383, 2009.

[37] D. C. Whitehair, A. Sherzai, J. Emond et al., "Influence of apolipoprotein E varepsilon4 on rates of cognitive and functional decline in mild cognitive impairment," Alzheimer's ¿ Dementia, vol. 6, no. 5, pp. 412-419, 2010.

[38] K. Yaffe, A. J. Fiocco, K. Lindquist et al., "Predictors of maintaining cognitive function in older adults: the health $\mathrm{ABC}$ study," Neurology, vol. 72, no. 23, pp. 2029-2035, 2009.

[39] M. Thambisetty, L. Beason-Held, Y. An, M. A. Kraut, and S. M. Resnick, "APOE $\varepsilon 4$ genotype and longitudinal changes in cerebral blood flow in normal aging," Archives of Neurology, vol. 67, no. 1, pp. 93-98, 2010.

[40] N. Raz, K. M. Rodrigue, K. M. Kennedy, and S. Land, "Genetic and vascular modifiers of age-sensitive cognitive skills: effects of COMT, BDNF, ApoE, and hypertension," Neuropsychology, vol. 23, no. 1, pp. 105-116, 2009.

[41] A. Barabash, A. Marcos, I. Ancín et al., "APOE, ACT and CHRNA7 genes in the conversion from amnestic mild cognitive impairment to Alzheimer's disease," Neurobiology of Aging, vol. 30, no. 8, pp. 1254-1264, 2009.

[42] P. N. Wang, H. C. Liu, J. F. Lirng, K. N. Lin, and Z. A. $\mathrm{Wu}$, "Accelerated hippocampal atrophy rates in stable and progressive amnestic mild cognitive impairment," Psychiatry Research, vol. 171, no. 3, pp. 221-231, 2009.

[43] R. Heun, U. Gühne, T. Luck et al., "Apolipoprotein E allele 4 is not a sufficient or a necessary predictor of the development of Mild Cognitive Impairment," European Psychiatry, vol. 25, no. 1, pp. 15-18, 2010.

[44] J. R. Carrión-Baralt, J. Meléndez-Cabrero, H. Rodríguez-Ubias et al., "Impact of APOE $\varepsilon 4$ on the cognitive performance of a sample of non-demented puerto rican nonagenarians," Journal of Alzheimer's Disease, vol. 18, no. 3, pp. 533-540, 2009.

[45] N. A. Kozauer, M. M. Mielke, G. K. Chuen Chan, G. W. Rebok, and C. G. Lyketsos, "Apolipoprotein E genotype and lifetime cognitive decline," International Psychogeriatrics, vol. 20, no. 1, pp. 109-123, 2008.

[46] C. R. A. Mondadori, D. J. F. De Quervain, A. Buchmann et al., "Better memory and neural efficiency in young apolipoprotein E $\varepsilon 4$ carriers," Cerebral Cortex, vol. 17, no. 8, pp. 1934-1947, 2007.

[47] D. Gozal, O. S. Capdevila, L. Kheirandish-Gozal, and V. M. Crabtree, "APOE $\varepsilon 4$ allele, cognitive dysfunction, and obstructive sleep apnea in children," Neurology, vol. 69, no. 3, pp. 243-249, 2007.

[48] F. Liu, L. M. Pardo, M. Schuur et al., "The apolipoprotein E gene and its age-specific effects on cognitive function," Neurobiology of Aging, vol. 31, no. 10, pp. 1831-1833, 2008.
[49] F. M. Filbey, K. J. Slack, T. P. Sunderland, and R. M. Cohen, "Functional magnetic resonance imaging and magnetoencephalography differences associated with APOE\&4 in young healthy adults," NeuroReport, vol. 17, no. 15, pp. 1585-1590, 2006.

[50] A. J. Trachtenberg, N. Filippini, and C. E. Mackay, "The effects of APOE- $\varepsilon 4$ on the BOLD response," Neurobiology of Aging. In press.

[51] S. Y. Bookheimer, M. H. Strojwas, M. S. Cohen et al., "Patterns of brain activation in people at risk for Alzheimer's disease," New England Journal of Medicine, vol. 343, no. 7, pp. 450-456, 2000.

[52] B. C. Dickerson, D. H. Salat, D. N. Greve et al., "Increased hippocampal activation in mild cognitive impairment compared to normal aging and AD," Neurology, vol. 65, no. 3, pp. 404$411,2005$.

[53] M. W. Bondi, W. S. Houston, L. T. Eyler, and G. G. Brown, "fMRI evidence of compensatory mechanisms in older adults at genetic risk for Alzheimer disease," Neurology, vol. 64, no. 3, pp. 501-508, 2005.

[54] S. C. Johnson, M. L. Ries, T. M. Hess et al., "Effect of alzheimer disease risk on brain function during self-appraisal in healthy middle-aged adults," Archives of General Psychiatry, vol. 64, no. 10, pp. 1163-1171, 2007.

[55] S. C. Johnson, T. W. Schmitz, M. A. Trivedi et al., "The influence of Alzheimer disease family history and apolipoprotein E $\varepsilon 4$ on mesial temporal lobe activation," Journal of Neuroscience, vol. 26, no. 22, pp. 6069-6076, 2006.

[56] J. Lind, J. Persson, M. Ingvar et al., "Reduced functional brain activity response in cognitively intact apolipoprotein E $\varepsilon 4$ carriers," Brain, vol. 129, no. 5, pp. 1240-1248, 2006.

[57] M. D'Esposito, L. Y. Deouell, and A. Gazzaley, "Alterations in the bold fMRI signal with ageing and disease: a challenge for neuroimaging," Nature Reviews Neuroscience, vol. 4, no. 11, pp. 863-872, 2003.

[58] K. J. Bangen, K. Restom, T. T. Liu et al., "Differential age effects on cerebral blood flow and BOLD response to encoding: associations with cognition and stroke risk," Neurobiology of Aging, vol. 30, no. 8, pp. 1276-1287, 2009.

[59] Y. F. Chuang, K. M. Hayden, M. C. Norton et al., "Association between APOE $\varepsilon 4$ allele and vascular dementia: the cache county study," Dementia and Geriatric Cognitive Disorders, vol. 29, no. 3, pp. 248-253, 2010.

[60] D. Zade, A. Beiser, R. McGlinchey et al., "Interactive effects of apolipoprotein E type 4 genotype and cerebrovascular risk on neuropsychological performance and structural brain changes," Journal of Stroke and Cerebrovascular Diseases, vol. 19, no. 4, pp. 261-268, 2010.

[61] A. J. Fiocco, N. P. V. Nair, G. Schwartz et al., "Influence of genetic polymorphisms in the apolipoprotein (APOE) and the butyrylcholinesterase (BCHE) gene on stress markers in older adults: a 3-year study," Neurobiology of Aging, vol. 30, no. 6, pp. 1001-1005, 2009.

[62] I. Reinvang, A. J. Lundervold, E. Wehling, H. Rootwelt, and T. Espeseth, "Epistasis between APOE and nicotinic receptor gene CHRNA4 in age related cognitive function and decline," Journal of the International Neuropsychological Society, vol. 16, no. 3, pp. 424-432, 2010.

[63] C. Qiu and L. Fratiglioni, "Apolipoprotein E epsilon4 status and cognitive decline with and without dementia," Archives of Neurology, vol. 67, no. 8, p. 1036, 2010.

[64] A. Van Der Walt, J. Stankovich, M. Bahlo et al., "Apolipoprotein genotype does not influence MS severity, cognition, or 
brain atrophy," Neurology, vol. 73, no. 13, pp. 1018-1025, 2009.

[65] M. Brys, E. Pirraglia, K. Rich et al., "Prediction and longitudinal study of CSF biomarkers in mild cognitive impairment," Neurobiology of Aging, vol. 30, no. 5, pp. 682-690, 2009.

[66] E. M. Reiman, K. Chen, X. Liu et al., "Fibrillar amyloid- $\beta$ burden in cognitively normal people at 3 levels of genetic risk for Alzheimer's disease," Proceedings of the National Academy of Sciences of the United States of America, vol. 106, no. 16, pp. 6820-6825, 2009.

[67] C. Reitz and R. Mayeux, "Endophenotypes in normal brain morphology and Alzheimer's disease: a review," Neuroscience, vol. 164, no. 1, pp. 174-190, 2009.

[68] L. M. Shaw, H. Vanderstichele, M. Knapik-Czajka et al., "Cerebrospinal fluid biomarker signature in alzheimer's disease neuroimaging initiative subjects," Annals of Neurology, vol. 65, no. 4, pp. 403-413, 2009.

[69] P. Vemuri, H. J. Wiste, S. D. Weigand et al., "Effect of apolipoprotein E on biomarkers of amyloid load and neuronal pathology in Alzheimer disease," Annals of Neurology, vol. 67, no. 3, pp. 308-316, 2010.

[70] A. M. Fjell, K. B. Walhovd, C. Fennema-Notestine et al., "CSF biomarkers in prediction of cerebral and clinical change in mild cognitive impairment and Alzheimer's disease," Journal of Neuroscience, vol. 30, no. 6, pp. 2088-2101, 2010. 


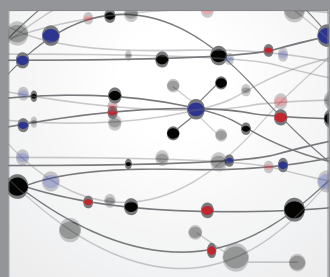

The Scientific World Journal
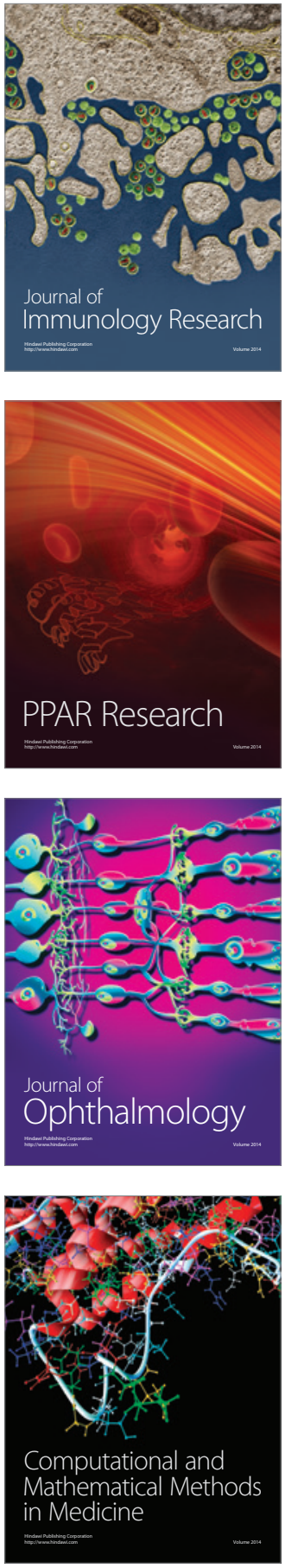

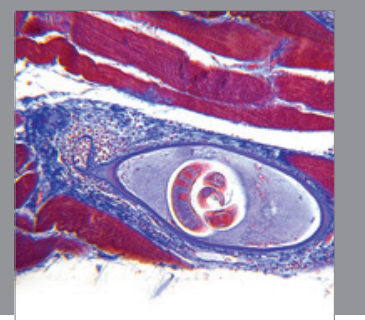

Gastroenterology

Research and Practice
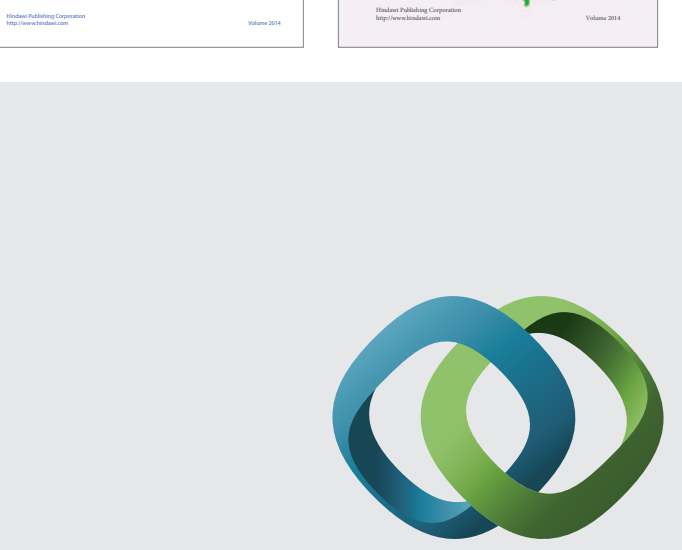

\section{Hindawi}

Submit your manuscripts at

http://www.hindawi.com
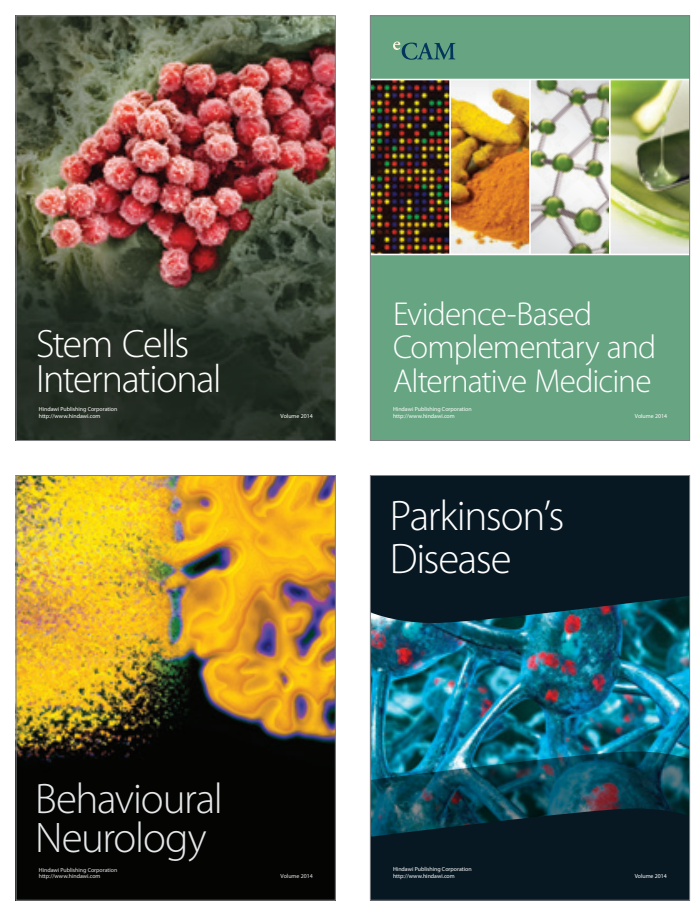

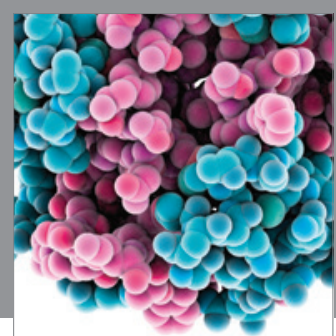

Journal of
Diabetes Research

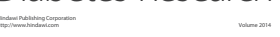

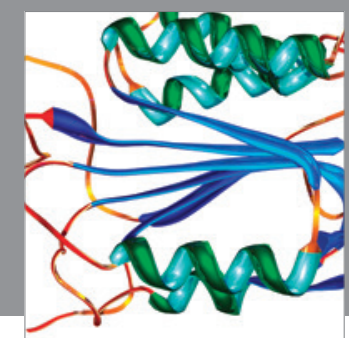

Disease Markers
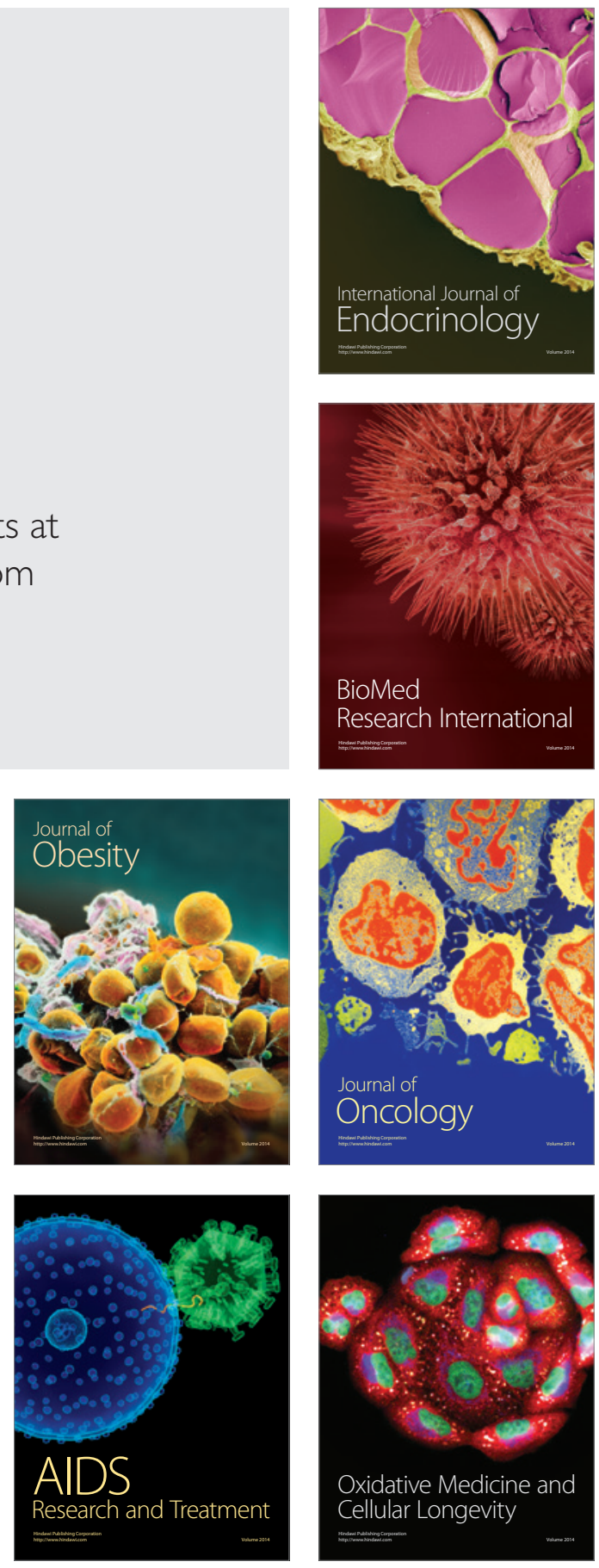